\title{
Nachtrag zu meiner Arbeit über den Bau der Nervenfasern ${ }^{1}$ ). \\ Von
}

\section{Dr. P. Schiefferdecker.}

In meiner Arbeit „Beiträge zur Kenntniss des Baus der Nervenfasern" (dieses Archiv, dieser Band p. 435 n. folg.) habe ich, worauf ich gleich nach dem Erscheinen der Arbeit aufmerksam gemacht wurde, eine Mittheilung nicht erwähnt, welche hätte erwähnt werden miissen. Ich habe dieselbe bei der Literaturdurchsicht übersehen, wofür ich um Entschuldigung bitte. F. Tourneux und R. Le Goff haben schon 1875 gefunden, dass sich am Rückenmarke des Ochsen nach Behandlung mit Arg. nitr. $1: 1000$ dieselben Silberquerstreifen resp. Kreuze zeigen, wie an den peripheren Nerven. Sie sagen am Schlusse:

"Il est assez difficile de se rendre compte de la nature de ces étranglements, autrement que par l'existence d'un disque qui interrompait la myéline de place en place et qui serait d'une substance jouissant de la propriété de décomposer le nitrate d'argent. Du reste, le précipité qui existe au niveau des étranglements ne persiste pas toujours sur les préparations comme celui qui se produit entre les cellules épithéliales des sẻreuses par exemple; c'est ainsi que sur des tubes nerveux périphériques nous avons pu voir la coloration noirâtre de l'étranglement disparâitre peu $\grave{a}$ peu, et ne laisser qu'un disque réfringent te même forme que celui dâ au dépôt métallique et indépendant de la gaîne de Schwann.

Nous devons ajouter que le procédé que nous avons employé ne nous a pas montré dans les tubes nerreux centraux, l'existence

1) Dieses Archiv, Bd. XXX, p. 435.

2) F. Tourneux und A. R. Le Go ff, Note sur les étranglements des tubes nerveux de la moëlle épinière. Robin, Journ. de l'anat. etc. p. 403$404,1875$. 
de la gaîne de Sehwann si visible dans les tubes nerveux périphériques."

Die eben mitgetheilten Resultate stimmen mit den von mir publicirten sehr gut. Leider scheinen die Verfasser ihre Absicht, die betreffenden Uutersuchungen weiter fortzusetzen, nicht ausgeführt zu haben und es ist bei jener kurzen Mittheilung geblieben.

Inzwischen habe ich dann noch Gelegenheit gehabt Nerren von frischen Neunaugen zu untersuchen. Die Thiere gelangten allerdings nicht mehr lebend, aber doch so kurze Zeit nach ihrem Ableben in meine Hände, dass man wohl die Nerven als gut erhalten ansehen konnte. Ich habe die letzteren sowohl frisch in Kochsalzlösung, wie nach Behandlung mit Ammon. bichrom. 1:1000 untersucht, bin indessen in Bezug auf die Fibrillen zu demselben negativen Resultate gelangt, wie bei meinen fruberen Untersuchungen, und doch kann man sich giinstigere Objecte als die dicken Axencylinder der Müller'schen Fasern kaum denken. Die Axencylinder zeigten stets sebr deutlich jenen schon beschriebenen Körnchenzug in der Mitte gegenüber einer mebr homogenen Randpartie. Bei Querschnitten von Präparaten aus Müller'scher Flüssigkeit erschienen dieselben als ein stark körniger, dunklerer, centraler kreisförmiger Theil und ein bellerer, mehr homogener, jenen umgebender Ring, beide ziemlich scharf gegeneinander abgesetzt, ganz entsprechend den Bildern, die ich auch vom Stör-Riickenmarke schon beschrieb. Ich bin dadurch noch mehr der Ansicht geworden, dass die Mauthner'sche Scheide anf diese Differenzirung des Axencylinders zu beziehen ist. Bei quer zerrissenen Fasern aus Ammon. bichr. 1:1000 zeigte sich das Ende oft etwas kegelförmig, derart, dass der mittlere körnige Theil der Faser ziemlich genau quer abgerissen etwas aus der übrigen Faser hervorragte, von ihm aus fiel dann der homogene Theil kegelförmig nach aussen $\mathrm{ab}$. Icb habe solche Bilder schon bei meinen früheren Untersuchungen mehrfach gesehen auch bei höberen Thieren, z. B. bei Fasern aus einem mittels Methylmixtur macerirten Riickenmarke vom Kalbe. Es macht diese Erscheinung den Eindruck, als wenn die Mitte der Faser wieder zäher wäre als die Randpartie. Bei den feineren Fasern des Neunauges tritt tibrigens die homogene Randpartie mehr und mehr zurück gegenüber der mittleren körnchenführenden. Es macht dieser Umstand es wahrscheinlich, dass die Körnchenzone das wesentlichste, die Randpartie eine Um- 
102 Dr. P. Schiefferdecker: Nachtrag zu meiner Arbeit über den Bau etc.

hüllung jener darstellt, und es wäre ja möglich, dass bei den feineren Nerven der höheren Thiere diese bomogene Umhilllungsschicht recht dün geworden wäre, wodurch dann ein deutliches Wahrnehmen einer Mauthner'schen Scheide auf dem Querschnitte unmöglieh würde. Bei der kurzen Zeit, die mir für diese letzten Untersuchungen zu Gebote stand, habe ich in Bezug hierauf keine weiteren Nachforschungen anstellen können und auch die Litteratur nicht mehr berikcksichtigen können.

In Bezug auf die Axencylinderrinde verhielten sich die Fasern des Neunauges ganz so wie die der anderen von mir untersuchten Thiere. Dieselbe war als eine sehr feine Umgrenzung sichtbar, die sich niemals von der Oberfläche der Faser abhob. Bei Behandlung mit Essigsäure trat bei dem Neunauge nicht jene sturmische Entwickelung von Vacuolen auf, wie ich sie bei den Axencylindern des Frosches fand. Die Substanz des Axencylinders wurde einfach sehr hell, auch die Axencylinderrinde, die indessen nun ebenso wie beim Frosehe deutlicher hervortrat, wenn auch nicht so scharf wie bei diesem Thiere. Es scheint danach also, als wenn in Bezug auf die chemische Beschaffenheit des Axencylinders bedentendere Unterschiede zwischen Neunauge und Frosch vorhanden wären. Doch auch diesen Punkt, über den Näheres zu wissen von grosser Wichtigkeit wäre, habe ich zunächst nicht weiter verfolgen können. 